\title{
Favorable Hodgkin Lymphoma
}

National Cancer Institute

\section{Source}

National Cancer Institute. Favorable Hodgkin Lymphoma. NCI Thesaurus. Code C68660.

A Hodgkin lymphoma with favorable prognosis. 